\title{
Investigation on Suitability of Aluminium to Copper in a Radiator
}

\author{
Anand Kumar Dubey \\ RKDF Institute of Science \& Technology, RGPV University, India
}

Copyright (c) 2015 Horizon Research Publishing All rights reserved.

\begin{abstract}
During the development of automobile it was a bigger challenge to prevent the engine \& engine components from melting \& damages because the heat generated \& temperature inside the cylinder is more than the melting points of engine components due to combustion of fuel inside the cylinder. Many researchers \& scientist started working for making the arrangement to dissipate the heat of considerable amount to avoid such bigger problem otherwise engine will seize. After a lot of research work on different types of materials to conduct the heat efficiently they came to conclusion that copper is the best material having good thermal conductivity of 385 watt $/ \mathrm{m}-\mathrm{K}$ can be used in the form of heat exchanger \& finally they designed a radiator called "COPPER RADIATOR". It is in continuous use in all types of automobile across the world. Over a period due to various pressure of availability, manufacturability, performance, reliability, cost, handling, weight researchers started working on use of alternate materials in a radiator in place of copper to match the performance same as copper \& getting other benefits. Attempts have been tried on different kinds of materials \& finally found that Aluminium can solve our problem \& it will meet most of our objectives \& requirements. So, finally it has been decided to make "Aluminium Radiator" in place of Copper radiators which will give benefits in performance, reliability, cost, availability, easy in handling \& manufacturing. The design $\&$ development techniques will be discussed subsequently. The effort of this project is to replace the costly copper radiator used in automobile by Aluminium radiator for better reliability, cost benefit, weight reduction \& desirable performance. The Aluminium radiator has a number of features that make it very attractive for vehicle applications in general. Superior durability and reliability in conjunction with its excellent specific values for costs, performance and weight warrant a favorable solution for Heavy Duty Trucks, tractors, Car, earth movers $\&$ other Automobile segments. This methodology examines the results based on design, lab testing, and field testing in actual condition. It reviews the field experience compared to Copper/Brass radiators, examines design and mounting features. Durability, external and internal corrosion resistance are emphasized as essential characteristics. A
\end{abstract}

special focus is the thermodynamics of Aluminium radiators. The result obtained has been summarized as below:(a) Aluminium Radiator is able to transfer the heat of 27.95 $\mathrm{KW}$ same as Copper Radiator. This is the $1 / 3^{\text {rd }}$ amount of heat generated in the engine to be dissipated. (b) Cost Reduction of Amount Rs 1923/- it is about 49\% saving against existing cost of Copper Radiator. (c) Weight Reduction of $5 \mathrm{Kg}$, it is $52.08 \%$ reduction in weight due to use of Aluminium Radiator.(d) Reliability \& Field Performance is as per copper Radiator, there is no field failure within the warranty period in all types of applications.

Keywords Heat Transfer, Thermal Analysis, Alternate Material, Log Mean Temperature Difference, Overall Heat Transfer Coefficient, Heat Exchanger

\section{Introduction}

As on current scenario due to unstable economic condition \& continuously increasing in commodity prices like steel, petroleum, coal \& minerals, electrical \& electronic equipment's \& general purpose things the manufacturing cost of a product is getting increases Due to increase in cost \& competitions between the competitors there is huge pressure in cost reduction \& better quality to be pass to the customer to run the industries \& stand in markets among all similar product.

In automobile industries Radiator is a prime component of any vehicle like car, Bus $\&$ Truck, Tractors etc. \& play very important role in the cost \& performance of vehicle. A radiator is a type of heat exchanger. It is designed to transfer heat from the hot water flowing through it to the air blown through it by the fan. These radiators are made by brazing thin Aluminium fins to flattened Aluminium tubes. The coolant flows from the inlet to the outlet through many tubes and transfer heat to the air flowing through the radiator. Currently all automobile industries are using Copper based Radiator. The focus is to replace this Copper Radiator by Aluminium Radiator which has better 
Reliability, performance, light weight \& major cost benefit as a whole product in comparison to Copper radiator. Aluminium has a number of features which make it superior to the other non-ferrous metals (copper and brass) normally used for radiators in the past. Apart from the low specific weight, there are additional advantages, such as outstanding heat conductivity, strength, corrosion resistance and convenient forming and processing qualities. Brazed Aluminium radiators with flat tubes and louvered serpentine fins are used for high horsepower engines and/or in confined spaces, while mechanically assembled round tube or oval tube radiators are preferred for smaller engines and/or where there is sufficient space.

The excellent field results with car radiators have led to the use of Aluminium radiators in trucks as well. The weight of radiator systems in cars and vans has been reduced by more than $50 \%$ or approximately 5 to $7 \mathrm{~kg}$, accounting for up to $1 \%$ of the vehicle weight.

Modern automotive internal combustion engines generate a huge amount of heat. This heat is created when the gasoline and air mixture is ignited in the combustion chamber. This explosion causes the piston to be forced down inside the engine, levering the connecting rods, and turning the crankshaft, creating power. Metal temperatures around the combustion chamber can exceed $537^{\circ} \mathrm{C}$. In order to prevent the overheating of the engine oil, cylinder walls, pistons, valves, and other components by these extreme temperatures, it is necessary to effectively dispose of the heat. It has been stated that a typical average-sized vehicle can generate enough heat to keep a 5-room house comfortably warm during zero degree weather. Approximately $1 / 3$ of the heat in combustion is converted into power to drive the vehicle and its accessories. Another $1 / 3$ of the heat is carried off into the atmosphere through the exhaust system. The remaining $1 / 3$ must be removed from the engine by the cooling system. Modern automotive engines have basically dumped the Air Cooled System for the more effective Liquid Cooled System to handle the job. In a liquid cooled system, heat is carried away by the use of a heat absorbing coolant that circulates through the engine, especially around the combustion chamber in the cylinder head area of the engine block. The coolant is pumped through the engine, then after absorbing the heat of combustion is circulated to the radiator where the heat is transferred to the atmosphere. The cooled liquid is then transferred back into the engine to repeat the process. Excessive cooling system capacity can also be harmful, and may affect engine life and performance. One must understand that coolant temperatures also affect oil temperatures and more engine wear occurs when the engine oil is below $88^{\circ} \mathrm{C}$. An effective cooling system controls the engine temperature within a specific range so that the engine stays within peak performance.

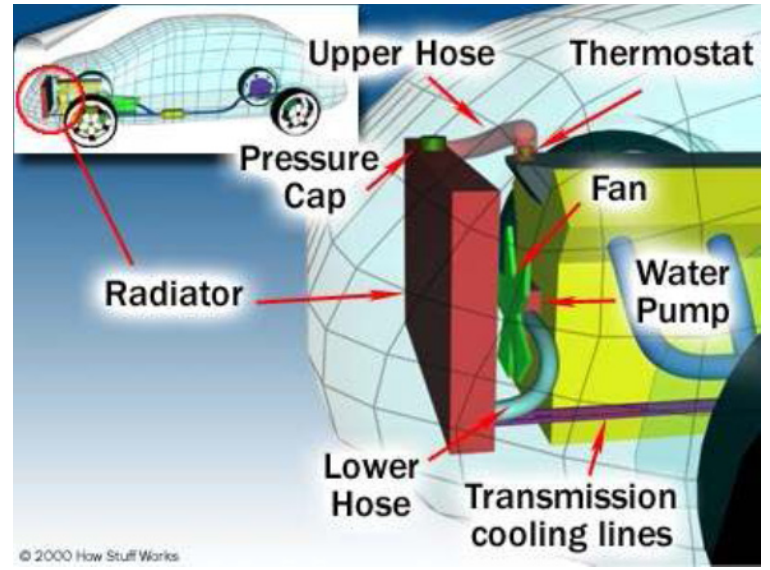

Figure 1. Automotive Cooling System

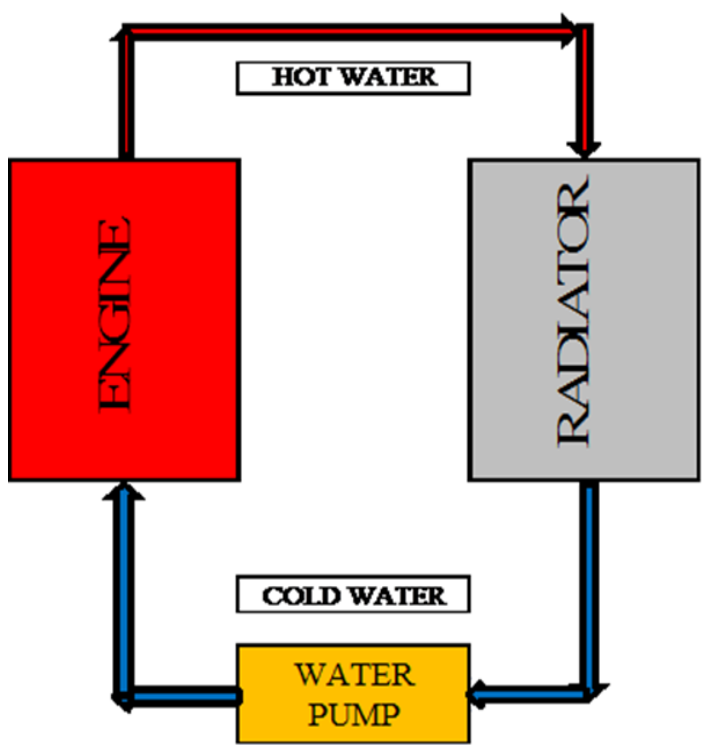

Figure 2. Automotive Cooling Cycle

Radiator: A radiator is a type of heat exchanger. It is designed to transfer heat from the hot water flowing through it to the air blown through it by the fan. Most modern cars use aluminum radiators. These radiators are made by brazing thin aluminum fins to flattened aluminum tubes. The coolant flows from the inlet to the outlet rough many conducts the heat from the tubes and transfers it to the air flowing through the radiator.

\section{Materials and Methods}

\subsection{Need of Radiator}

Cost Benefits: Due to continuous increasing in commodity prices the cost of product increases which affect the financial condition of end customers. Copper is being used currently hence, the need for cheaper materials.

Weight Reduction: The weight of radiator systems to be reduced for saving in fuel. 
Better Performance \& Reliability: The performance \& reliability to ensure greater heat transfer rate by increasing in surface area more than in copper radiator.

\subsection{Thermal Analysis}

In general, there are three mechanisms of heat transfer. These mechanisms are conduction, convection and radiation. Thermal analysis calculates the temperature distribution in a body due to some or all of these mechanisms. In all three mechanisms, heat energy flows from the medium with higher temperature to the medium with lower temperature. Heat transfer by conduction and convection requires the presence of an intervening medium while heat transfer by radiation does not.

Mode of Heat Transfer -

- Conduction

- Convection

- Radiation

\subsubsection{Conduction}

Thermal conduction is a mechanism of heat propagation from a region of higher temperature to lower temperature within a medium (solid, liquid or gas) or between different mediums in direct physical contact. The thermal energy transfer by means of electrons which are free to move through the lattice structure of the materials.

\subsubsection{Convection Heat Transfer}

Convection is the heat transfer mode in which heat transfers between a solid face and an adjacent moving fluid. The layer of the fluid adjacent to the hot surface becomes warmer; its density decreases and becomes buoyant. A cooler fluid near the surface replaces the warmer fluid and a pattern of circulation forms. The heat transfer in this pattern is known as convection heat transfer.

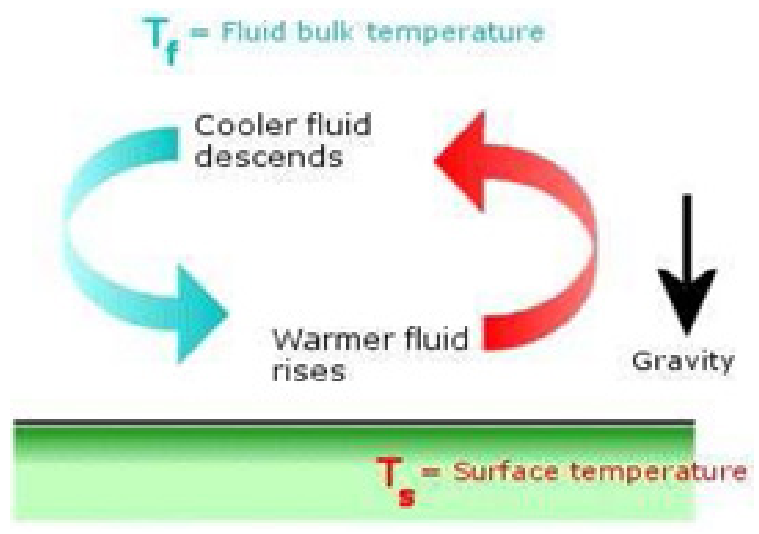

Figure 3. Convective Heat transfer

Convection is the heat transfer mode in which heat transfers between a solid face and an adjacent moving fluid. The layer of the fluid adjacent to the hot surface becomes warmer; its density decreases and becomes buoyant. A cooler fluid near the surface replaces the warmer fluid and a pattern of circulation forms. The rate of heat exchange between a fluid of temperature T1 (cold fluid) and a face of a solid of area A at temperature T2 (hot fluid) obeys the Newton's law of cooling which can be written as:

$$
\mathrm{Q}=\mathrm{hA}(\mathrm{T} 2-\mathrm{T} 1)
$$

Where $\mathrm{h}$ is the convection heat transfer coefficient. The unit of $\mathrm{h}$ is $\mathrm{W} / \mathrm{m} 2 \mathrm{~K} . \mathrm{h}$ is the convection heat transfer coefficient \& A is surface area.

Thermal heat Conduction Equation:

$$
\mathrm{Q}=\mathrm{KA}(\mathrm{T} 1-\mathrm{T} 2) / \mathrm{L}
$$

Where $\mathrm{K}$ is conduction heat transfer coefficient, T1, T2 inlet \& outlet temp, L is Thickness of wall.

\subsubsection{Modes of Convection Heat Transfer:}

(A) Natural Convection: The motion of the fluid adjacent to a solid face is caused by buoyancy forces induced by changes in the density of the fluid due to differences in temperature between the solid and the fluid. When a hot plate is left to cool down in the air the particles of air adjacent to the face of the plate get warmer, their density decreases, and hence they move upward.

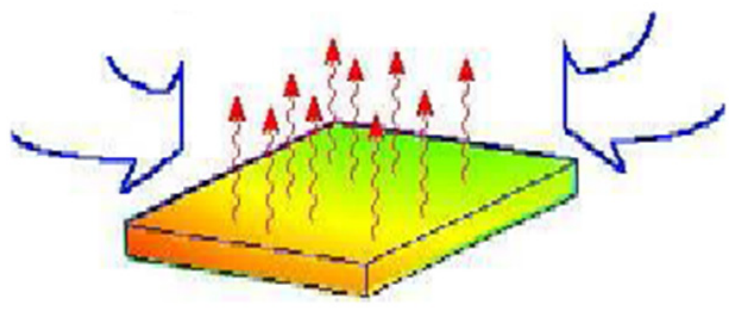

Figure 4. Natural Convection

(B) Forced Convection: An external means such as a fan or a pump is used to accelerate the flow of the fluid over the face of the solid. The rapid motion of the fluid particles over the face of the solid maximizes the temperature gradient and increases the rate of heat exchange. In the Following image, air is forced over a hot plate.

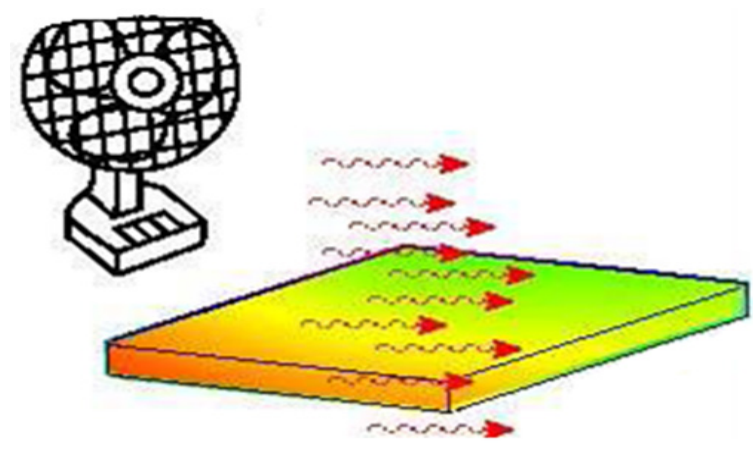

Figure 5. Forced Convection

\subsection{Approach}

An existing cooling system will be studied and evaluated. In the designing stage, features and dimensions for the radiator will be fully defined and measured. Choosing the 
right radiator's material and deciding if the material has been chosen is good enough to keep the radiator running without any overheating during the real conditions.

\subsection{Working Principle \& Calculation}

Radiator is a cross flow heat exchanger in which we try to transfer the heat from one fluid (hot water) to other fluid (Air) by means of heat exchange principle. As per thermal calculation for cross flow heat exchanger with one fluid mixed \& other fluid unmixed, the heat exchange rate is given by

$$
\begin{array}{r}
\mathrm{Q}=\text { FUA } \theta \mathrm{m} \\
\theta_{\mathrm{m}}=\frac{\theta_{1}-\theta_{2}}{\log \left(\theta_{1} / \theta_{2}\right)}
\end{array}
$$

$\theta \mathrm{m}=\log$ mean temperature difference.

$\theta 1=$ Thermal head at inlet

$\theta 2=$ Thermal head at outlet

$\mathrm{U}=$ overall heat transfer coefficient

$\mathrm{A}=$ Heat transfer surface area.

$\mathrm{F}=$ Correction factor for heat transfer for cross flow with one fluid mixed \& other unmixed.

As per principle of design of engine \& radiator $1 / 3 \mathrm{rd}$ of heat generated in the engine to be transferred through radiator, for our case it comes to about $27 \mathrm{KW}$ of heat to be transferred by the radiator.

Observation:

Water inlet temp $\mathrm{T}_{\mathrm{wl}}=91.67^{\circ} \mathrm{C}$

Water outlet temp $\mathrm{T}_{\mathrm{w} 2}=79^{\circ} \mathrm{C}$

Air inlet temp $\mathrm{T}_{\mathrm{a} 1}=36.14^{\circ} \mathrm{C}$

Air Outlet temp $\mathrm{T}_{\mathrm{a} 2}=50.56^{\circ} \mathrm{C}$

For calculation of correction factor $\mathrm{F}$

$$
\begin{gathered}
Z=\frac{T_{w 1}-T_{w 2}}{T_{a 2}-T_{a 1}}=\frac{91.67-79}{50.56-36.14} \\
\mathrm{Z}=0.878 \\
P=\frac{T_{w 1}-T_{w 2}}{T_{a 2}-T_{a 1}} \\
=\frac{50.56-36.14}{91.67-36.14} \\
\mathrm{P}=0.259
\end{gathered}
$$

According to the value of $\mathrm{P} \& \mathrm{Z}$ we can get the value of $\mathrm{F}$ from graph \& it comes to 0.97

$$
\mathrm{F}=0.97
$$

$\mathrm{Q}=27 \mathrm{KW}$ (for both Copper \& Aluminium Radiator)

Thermal head at inlet $\theta 1=$ Tw1-Ta1 $=91.67-36.14=55.53$

Thermal head at outlet $\theta 2=\mathrm{Tw} 1-\mathrm{Ta} 2$

$$
\begin{gathered}
=79-50.56 \\
=28.44
\end{gathered}
$$

$$
\begin{gathered}
\theta_{\mathrm{m}}=\frac{\theta_{1}-\theta_{2}}{\log \left(\theta_{1} / \theta_{2}\right)} \\
=\frac{55.53-28.44}{\log (55.53 / 28.44)} \\
\theta \mathrm{m}=40.48
\end{gathered}
$$

$\theta \mathrm{m}$ will be same for both type of Radiator .

From Equation (1)

Q is same for both type Radiators since it is the amount of heat to be transferred.

$\theta \mathrm{m}$ is same for both type of Radiator because it depend on inlet $\&$ outlet condition of Radiator.

$\mathrm{F}$ is constant since it is correction factor for the pattern of flow.

$$
\begin{aligned}
& \text { Then } U=\frac{1}{A} \\
& \frac{U 1}{U 2}=U=\frac{A 2}{A 1}
\end{aligned}
$$

Where,

$\mathrm{U}_{1}=$ Overall heat transfer coefficient for Copper Radiator $\mathrm{U}_{2}=$ Overall heat transfer coefficient for Aluminium Radiator

$A_{1}=$ Heat transfer Surface area for Copper Radiator $\mathrm{A}_{2}=$ Heat Transfer surface area for Aluminium Radiator Overall heat transfer coefficient Equation:

$$
\frac{1}{U}=\frac{1}{h_{i} A_{i}}+\frac{d X}{k A}+\frac{1}{h_{0} A_{0}}
$$

Where,

hi- Convective heat transfer coefficient in inner side of tube in $\mathrm{Watt} / \mathrm{m}^{2} \mathrm{~K}$

ho- Convective heat transfer coefficient in outer side of tube Watt $/ \mathrm{m}^{2} \mathrm{~K}$

dX-Thickness of tubes

Ai- Surface Area of inner tube $\mathrm{m}^{2}$

Ao- Surface area of outer tube $\mathrm{m}^{2}$

Here hi, Ai, dX, A, ho, Ao are constant hence UaK So,

$$
\frac{K_{1}}{K_{2}}=\frac{A_{2}}{A_{1}}
$$

$\mathrm{K}_{1}$ - Thermal Conductivity of Copper Watt $/ \mathrm{mK}$

$\mathrm{K}_{2}$ - Thermal conductivity of Aluminium Watt $/ \mathrm{mK}$

$\mathrm{K}_{1}=385 \mathrm{Watt} / \mathrm{mK}$

$\mathrm{K}_{2}=225 \mathrm{Watt} / \mathrm{mK}$

$$
\frac{A_{2}}{A_{1}}=1.71
$$

Heat transfer area of Copper Radiator $\mathrm{A} 1=3.6 \mathrm{~m}^{2}$ So $\mathrm{A}_{2}=1.71 \mathrm{X} 3.6$ 


\section{$A_{2}=6.21 \mathrm{~m}^{2}$}

Hence heat transfer area of Aluminium radiator will be required about $6.21 \mathrm{~m}^{2}$ to transfer the same amount of heat as copper Radiator.

As per above Equation no (5) we conclude that to transfer the same amount of heat from aluminium radiator against the copper radiator the area of heat transfer to be increased by $71 \%$ with respect to copper radiator which can be accommodate in design by minimizing the gaps between the fins \& overall size of the Radiator.

In copper radiator the core size is $395 \times 397.9 \times 51$, no of fins are 122 nos, fin size (in mm) $0.05 \times 397.9 \times 51$, row of tubes is 3 and no of tubes are about 136 nos. By modification in design, spacing, pitch and arrangement the resize of aluminium core $380.4 \mathrm{X} 410 \mathrm{X} 36$ with pitch of $2 \mathrm{~mm}$ between the fins, core of brazed aluminium in 2 rows we achieved the fins area of $5.14 \mathrm{~m}^{2}$ tubes area of $1.06 \mathrm{~m}^{2}$ and hence total area of $6.21 \mathrm{~m}^{2}$ against the $3.6 \mathrm{~m}^{2}$ in copper radiator to match the same amount of heat transfer as copper radiator with comparable performance.

The further performance is tested in experimental setup by changing the parameters and then after validation field trial is undertaken.

\subsection{Overview of Experiment Set-up}

In the experiment of performance testing of aluminium radiator the radiator is mounted on the engine as actual application in the testing lab, coolant is filled in the radiator. The gauges for measurement of water flow rate \& air flow rate with variable value are fitted in which the value can be changed by means of circular knob as per required flow rate, temperature sensors are fitted at the inlet \& outlet points of water $\&$ air both which record the inlet $\&$ outlet temperature of the water \& air, pressure gauges are fitted at the inlet \& outlet of air \& water to record the pressure for the calculation of pressure drop. Before fitting all devices, they must be calibrated for accuracy of the experiments \& results.

After completion of arrangement \& set up engine started, the observation recorded as per observation table by varying the values of air flow \& water flow at certain point the desired output achieved $\&$ this is the required set parameter at which this designed radiator will work.

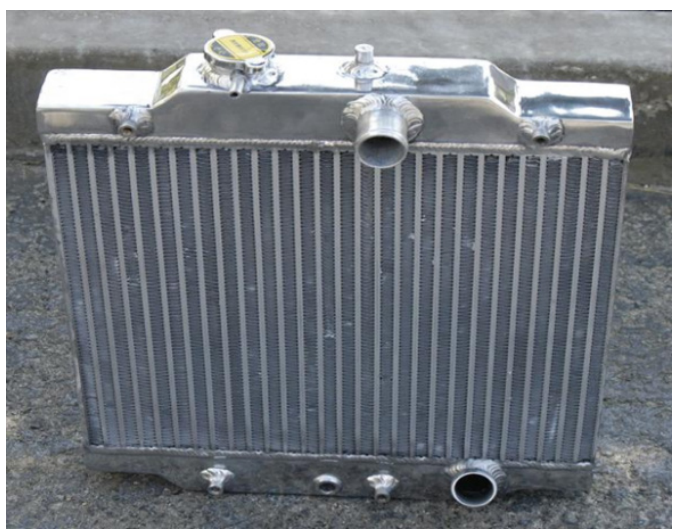

Figure 6. Current radiator

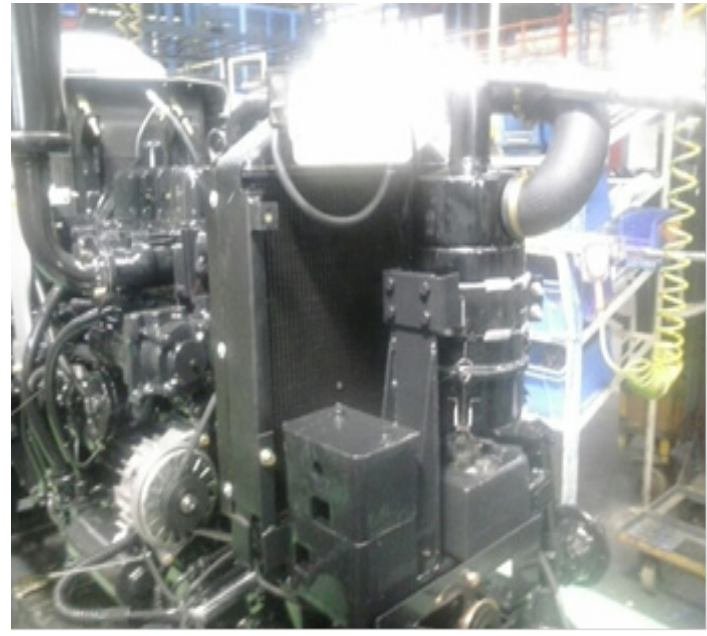

Figure 7. Experimental Radiator set-up

\subsection{Radiator Development Steps}

1. Aluminium Radiator is designed based on the requirement of Heat to be rejected by Radiator with the help of Simulation \& Modeling, Thermal calculation \& performance analysis.

2. Aluminium Radiator is produced through proto development for sample inspection \& testing on the vehicle as per actual application.

3. Heat performance testing is done at different air flow rate \& water flow rate to get desired heat dissipation by radiator.

4. After analysis \& getting desired result at a fixed air flow rate $\&$ water flow rate the other parameter will be fixed $\&$ incorporated in the drawing for actual application

Table 1. Test Condition \& Observation

\begin{tabular}{|c|c|c|c|}
\hline Test Parameter & $\begin{array}{c}\text { Unit of } \\
\text { Measurement }\end{array}$ & $\begin{array}{c}\text { Test } \\
\text { specification }\end{array}$ & Sample-1 \\
\hline Water Flow & $1 / \mathrm{min}$ & 33 & 33.1 \\
\hline Air Flow & $\mathrm{m} / \mathrm{s}$ & 11.63 & 11.65 \\
\hline Temp Difference & Deg C & 50 & 50 \\
\hline $\begin{array}{c}\text { Heat Rejection Capacity } \\
\text { Qw }\end{array}$ & $\mathrm{KW}$ & 26.8 & 26.67 \\
\hline $\begin{array}{c}\text { \% Change from design } \\
\text { specification }\end{array}$ & $\%$ & 10 & -0.49 \\
\hline air flow pressure drop & $\mathrm{Pa}$ & 213.6 & 198.4 \\
\hline $\begin{array}{c}\text { \%change from design } \\
\text { specification }\end{array}$ & $\%$ & 20 & -7.12 \\
\hline water flow pressure drop & $\mathrm{Kpa}$ & 3.3 & 2.9 \\
\hline $\begin{array}{c}\text { \% Change from design } \\
\text { specification }\end{array}$ & $\%$ & 20 & -12.12 \\
\hline
\end{tabular}

Table 2. Material property of $\mathrm{Al} \& \mathrm{Cu}$

\begin{tabular}{|c|c|c|c|}
\hline Description & Unit & Al & Copper \\
\hline Elastic Modulus & $\mathrm{GPa}$ & 69 & 11 \\
\hline Poison Ration & & 0.33 & 0.37 \\
\hline Shear Modulus & $\mathrm{GPa}$ & 27 & 40 \\
\hline Mass density & $\mathrm{Kg} / \mathrm{m} 3$ & 2700 & 8900 \\
\hline Tensile Strength & $\mathrm{MPa}$ & 68.93 & 394.38 \\
\hline Yield Strength & $\mathrm{MPa}$ & 0.2742 & 258.646 \\
\hline Thermal Conductivity & $\mathrm{W} / \mathrm{m}-\mathrm{K}$ & 225 & 385 \\
\hline
\end{tabular}


Table 3. Observation Table

\begin{tabular}{|c|c|c|c|c|c|c|c|c|c|c|c|c|c|c|c|c|}
\hline \multicolumn{2}{|c|}{ Air Flow } & \multicolumn{2}{|c|}{ Water Flow } & \multicolumn{3}{|c|}{ Water temp } & \multicolumn{2}{|c|}{ Air Temp } & \multirow{2}{*}{\begin{tabular}{|l|} 
Delta T \\
\\
\end{tabular}} & \multicolumn{2}{|c|}{ Pressure Drop } & \multirow{2}{*}{\multicolumn{2}{|c|}{$\begin{array}{c}\text { Heat dissipated } \\
\text { by Air }\end{array}$}} & \multirow{2}{*}{\multicolumn{2}{|c|}{$\begin{array}{c}\text { Heat Rejected } \\
\text { by water }\end{array}$}} & \multirow{3}{*}{$\frac{\text { Ratio }}{\text { Qa/Qw }}$} \\
\hline Set Point & Actual & Set Point & Actual & Hot water & \begin{tabular}{|c|} 
Radiator \\
Inlet
\end{tabular} & $\begin{array}{c}\text { Radiator } \\
\text { Outlet }\end{array}$ & $\begin{array}{c}\text { Radiator } \\
\text { Inlet }\end{array}$ & $\begin{array}{c}\text { Radiator } \\
\text { Outlet }\end{array}$ & & Water side & Air side & & & & & \\
\hline \multicolumn{2}{|c|}{$\mathrm{Va}$} & \multicolumn{2}{|c|}{ Vw } & \begin{tabular}{|l|} 
Tw0 \\
\end{tabular} & Tw1 & Tw2 & Ta1 & $\mathrm{Ta2}$ & Tw1-Ta1 & DPw & Dpa & Qa & Conv Qa & Qw & Conv Qw & \\
\hline $\mathrm{m} / \mathrm{s}$ & $\mathrm{Kg} / \mathrm{s}$ & $1 / \mathrm{mm}$ & $\mathrm{Kg} / \mathrm{s}$ & Deg C & Deg C & Deg C & Deg C & Deg C & Deg C & Kра & $\mathrm{Pa}$ & KW & $\mathrm{KW}$ & KW & KW & $\%$ \\
\hline 4 & 0.73 & 20 & 0.33 & 99.35 & 88.02 & 79.65 & 38.18 & 54.88 & 49.84 & 0.89 & 45.8 & 12.2 & 12.24 & 11.71 & 11.75 & $104.18 \%$ \\
\hline 4 & 0.74 & 33 & 0.55 & 98.23 & 87.97 & 82.68 & 38.3 & 56.6 & 49.67 & 2.83 & 49.2 & 13.57 & 13.66 & 12.32 & 12.41 & $110.15 \%$ \\
\hline 4 & 0.72 & 60 & 1.01 & 99.06 & 89.36 & 86.31 & 38.18 & 58.41 & 51.18 & 6.2 & 50.3 & 14.68 & 14.35 & 12.93 & 12.63 & $113.53 \%$ \\
\hline 4 & 0.71 & 80 & 1.35 & 98.36 & 89.08 & 86.93 & 38.2 & 58.66 & 50.88 & 8.73 & 43.2 & 14.62 & 14.37 & 12.16 & 11.95 & $120.23 \%$ \\
\hline 6 & 1.07 & 20 & 0.34 & 101.61 & 89.28 & 77.35 & 37.84 & 52.96 & 51.44 & 0.92 & 96.3 & 16.25 & 15.8 & 16.95 & 16.48 & $95.87 \%$ \\
\hline 6 & 1.09 & 33 & 0.55 & 102.26 & 91.94 & 83.76 & 37.69 & 56.15 & 54.25 & 3.12 & 89.2 & 20.15 & 18.57 & 19.02 & 17.53 & $105.94 \%$ \\
\hline 6 & 1.1 & 60 & 1.01 & 101.58 & 91.97 & 87.26 & 37.55 & 57.56 & 54.43 & 6.4 & 95.1 & 22.11 & 20.31 & 19.96 & 18.33 & $110.77 \%$ \\
\hline 6 & 1.11 & 80 & 1.35 & 101.13 & 91.61 & 88.14 & 37.49 & 57.96 & 54.12 & 8.78 & 94.5 & 22.71 & 20.99 & 19.61 & 18.12 & $115.81 \%$ \\
\hline 8 & 1.46 & 20 & 0.34 & 99.35 & 89.32 & 75.32 & 37.39 & 51.28 & 51.93 & 0.94 & 132.5 & 20.39 & 19.63 & 19.78 & 19.04 & $103.08 \%$ \\
\hline 8 & 1.45 & 33 & 0.55 & 100.91 & 89.96 & 80.27 & 37.29 & 53.26 & 52.67 & 2.73 & 135.4 & 23.29 & 22.11 & 22.51 & 21.36 & $103.47 \%$ \\
\hline 8 & 1.47 & 60 & 1.01 & 101.78 & 91.89 & 85.97 & 37.07 & 55.69 & 54.82 & 5.9 & 138.4 & 27.41 & 25 & 25.08 & 22.87 & $109.29 \%$ \\
\hline 8 & 1.46 & 80 & 1.34 & 100.91 & 91.47 & 87.16 & 37.02 & 56.11 & 54.45 & 9.1 & 141.2 & \begin{tabular}{|l|}
27.93 \\
\end{tabular} & 25.65 & 24.25 & 22.36 & $115.18 \%$ \\
\hline 11.63 & 2.13 & 20 & 0.33 & 102.12 & 89.91 & 72.36 & 36.13 & 27.7 & 53.78 & 0.96 & 209.3 & 24.75 & 23.01 & \begin{tabular}{|l|}
24.64 \\
\end{tabular} & 22.91 & $100.45 \%$ \\
\hline 11.63 & 2.09 & 33 & 0.56 & 101.85 & 91.67 & 79 & 36.14 & 50.56 & 55.54 & 2.9 & 198.4 & 30.32 & 27.3 & 29.62 & 26.67 & $102.36 \%$ \\
\hline 11.63 & 2.11 & 60 & 1.01 & 100.57 & 90.86 & 83.27 & 35.99 & 52.29 & 54.88 & 5.24 & 201.4 & 34.6 & 31.52 & 32.15 & 29.29 & $107.62 \%$ \\
\hline 11.63 & 2.1 & 80 & 1.35 & 99.31 & 89.77 & 84.17 & 35.93 & 52.54 & 53.84 & 9.3 & 187.4 & 35.04 & 32.54 & 31.7 & 29.44 & $110.54 \%$ \\
\hline
\end{tabular}

390

Temp.K.

385

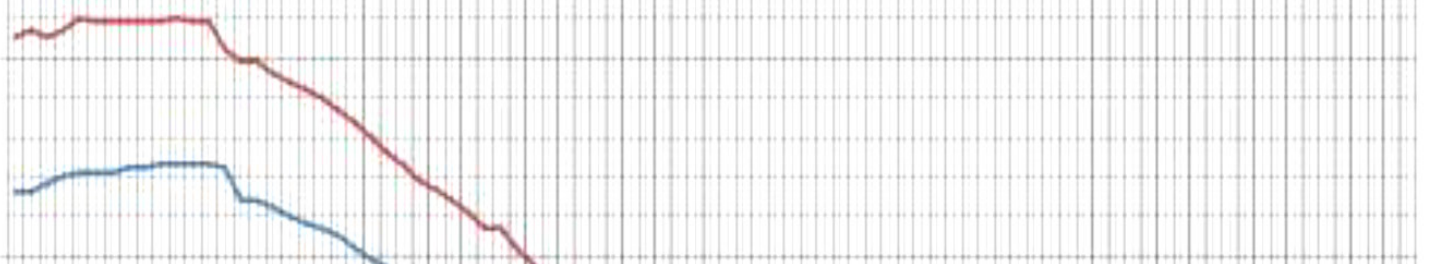

390

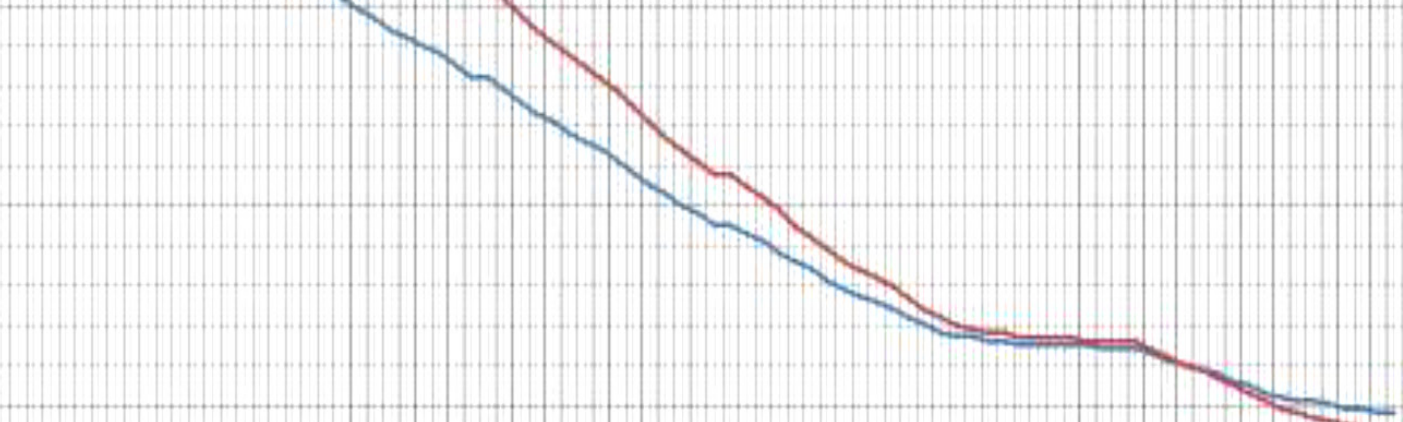

370

365

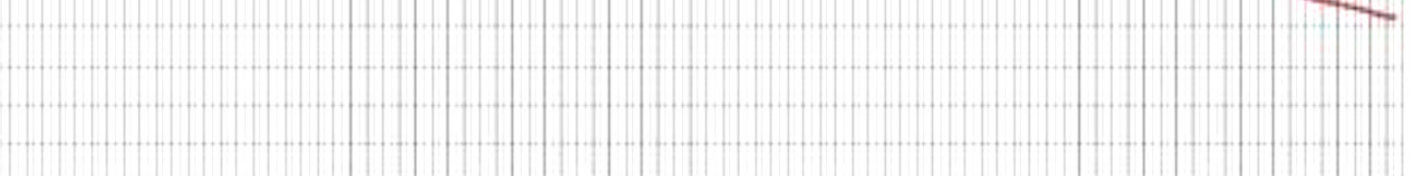

Figure 8. Aluminum \& Copper temp. Distribution 


\section{Acceptance Criteria}

Sample should meet the heat rejection capacity in the range $\pm 10 \%$ to actual rated value, Air \& water pressure drop of both sides in the range $\pm 20 \%$ to actual rated values.

\section{Conclusion \& Comments}

Subjected sample meets the acceptance criteria.

\subsection{Experimental Result \& Outcome}

After experiments \& thermal calculation the final geometrical parameter \& flow characteristics is tabulated as below.

\begin{tabular}{|c|c|c|c|c|}
\hline DIV & \multicolumn{2}{|c|}{ Heading } & Unit & Value \\
\hline \multirow{7}{*}{ Reference } & \multirow{7}{*}{ Condition } & Air Velocity & $\mathrm{m} / \mathrm{s}$ & 11.63 \\
\hline & & Coolant Flow & $1 / \min$ & 33 \\
\hline & & Temp Diff & $\mathrm{oC}$ & 55.54 \\
\hline & & Radiator Capacity & KW & 27.95 \\
\hline & & Air Resistance & $\mathrm{Pa}$ & 237.3 \\
\hline & & Coolant Resistance & $\mathrm{kPa}$ & 3.3 \\
\hline & & Test Pressure & $\mathrm{kPa}$ & 147 \\
\hline \multirow{13}{*}{ Structure } & \multirow{3}{*}{ Core Size } & Width & $\mathrm{mm}$ & 380.4 \\
\hline & & Height & $\mathrm{mm}$ & 410 \\
\hline & & Thickness & $\mathrm{mm}$ & 36 \\
\hline & \multicolumn{2}{|c|}{ Fin Pitch } & $\mathrm{mm}$ & $4.0 / 2$ \\
\hline & \multirow{3}{*}{$\begin{array}{c}\text { Radiation } \\
\text { Area }\end{array}$} & Fin & $\mathrm{mm}^{2}$ & 5.14 \\
\hline & & Tube & $\mathrm{mm}^{2}$ & 1.06 \\
\hline & & Total & $\mathrm{mm}^{2}$ & 6.21 \\
\hline & \multicolumn{2}{|c|}{ Front Area } & $\mathrm{mm}^{2}$ & 0.156 \\
\hline & \multicolumn{2}{|c|}{ Coolant Passage Area } & $\mathrm{cm}^{2}$ & 13.81 \\
\hline & \multicolumn{2}{|c|}{ Coolant Qty } & $\mathrm{L}$ & 1.9 \\
\hline & \multicolumn{2}{|c|}{ Dry Mass } & $\mathrm{Kg}$ & 4.8 \\
\hline & \multicolumn{2}{|c|}{ Core of brazed Aluminium } & Row & 2 \\
\hline & \multicolumn{2}{|c|}{ No of Tubes } & No & 76 \\
\hline
\end{tabular}

As per above experiment \& analysis Aluminium Radiator is able to transfer the heat from circulating water to atmospheric air by cross flow heat exchanger principle.

The Proposed Radiator meets all the functional requirement of Automobile Radiator. There is no side effect of Using the Aluminium in place of Copper in a Radiator.

\subsection{Cost Saving}

Based on Zero base costing for both Copper \& Aluminium Radiator, the cost saving is as below

Cost of Copper Radiator (A) - Rs 3905/-

Cost of Aluminium Radiator (B) - Rs 1982/-

Cost Saving (A-B) = Rs 1923/-

$\%$ Cost saving by using Aluminium Radiator $=49 \%$

\subsection{Weight Comparison:}

\begin{tabular}{|c|c|}
\hline Radiator & Weight $(\mathrm{Kg})$ \\
\hline Copper radiator & 9.6 \\
\hline Aluminium Radiator & 4.6 \\
\hline Saving In Weight & 5 \\
\hline \% Saving in weight & $\mathbf{5 2 . 0 8 \%}$ \\
\hline
\end{tabular}

\section{Results}

1. The reverse engineering has been implemented throughout the present work, in order to Achieve design analysis and improvement for the car radiator element.

2. Aluminium Radiator is able to transfer the heat of 27.95 KW same as Copper Radiator. This is the $1 / 3^{\text {rd }}$ amount of heat generated in the engine to be dissipated.

3. Cost Reduction of Amount Rs. 1923. It is about 49\% saving against existing cost of Copper Radiator.

4. Weight Reduction of $5 \mathrm{Kg}$; it is $52.08 \%$ reduction in weight due to use of Aluminium Radiator.

Reliability \& Field Performance is as per copper Radiator; there is no field failure within the defined life span.

\section{Discussion}

As per whole calculation, testing \& validation in actual application Aluminium Radiator is able to perform same as copper Radiator. One to one replacement is possible with desired objective without any adverse effect. So result is significant \& idea is beneficial to overcome the cost pressure on individual with good cost saving.

\section{Conclusions}

1. The efficiency of the internal combustion engine cooling system depends mainly on the Performance of its units. The main unit in this system is the radiator.

2. It has been concluded from exercise in previous chapters that by increasing the surface area of heat transfer Aluminium radiator can replace copper radiator with comparable performance, cheaper cost, light weight $\&$ fuel saving.

3. The Aluminium Radiator is able to perform same as Copper Radiator with some design modification, increasing the surface area of heat transfer \& it can replace the Copper Radiator in the respect of performance, heat transfer, cost competitive \& light weight.

4. Attractive features of aluminium radiator will make it implementation in very wide range of application throughout the world.

5. Since Copper is more costly \& difficult in availability the consumption of copper will reduce $\&$ it will be replaced 
by Aluminium which is available in bulk \& easily.

6 . Since the production of Vehicles in India is in very large scale, so is the requirement of Radiator in bulk Quantity, so by using Aluminium in Radiator the dependency on other country to get the copper will reduce \& we can utilize our own resources available in India at cheaper cost.

7. Painting of Tubes \& fins is more sensitive $\&$ required in Copper Radiator due to corrosion and oxidation problem but in case of Aluminium Radiator it is not so serious because scaling, oxidation \& corrosion is not so effective in the performance of Radiator.

Coloured oxides offer more resistance to heat transfer than white colour oxides. In case of copper Radiator coloured oxides are formed and affect the performance of Copper Radiator. But in case of Aluminium oxides white colour oxides formed $\&$ the effect of this white coloured oxide are less than Copper oxides.

8. Due to impurity in coolant used in Radiator \& continuous corrosion after aging the tubes got punctured \& leakage problem started in the field actual application; the reworking of these tubes is easy by brazing process in case of Aluminium Radiator than Copper Radiator but changing of tubes is very difficult in Aluminium Radiator which is a major drawback of Aluminium Radiator.

10. After detailed analysis \& above discussion it is recommended to use Aluminium radiator in all range of automobile, tractors, heavy machinery \& earthmovers.

\section{Acknowledgements}

I would like to express my greatest gratitude and respect to my supervisor Dr. M.K. Chopra (Vice Principal, Dean Academics \& Head, Department of Mechanical Engineering.), Prof. K.K. Puranik (Director) RKDFIST, Bhopal for his excellent guidance, valuable suggestions and endless support.

\section{REFERENCES}

[1] Akira Kawahara et al, Development of Aluminum Alloy Fin Stock for Heat Exchangers Using Twin-Roll Continuous Casting Method, Furukawa Review, No. 242003.

[2] Ack Howell Fair Oaks CA, Copper Radiator Application Analysis, USA 1993.

[3] Brandon Fell et. Al., High Efficiency Radiator Design for Advanced Coolant, ME450 Fall 2007.

[4] CAP A., Automotive Cooling System, Research \& development of HCV Germany.

[5] D. S. Kumar, Heat \& Mass Transfer, S. K. Kataria \& Sons, $6^{\text {th }}$ Edition 2001.

[6] D. Siddhartha, et al, Experimental and Numerical analysis of the thermal performance of Copper, Aluminium and Brass alloy radiators, Journal of Emerging Technology in Mechanical Science and Technology, (ISSN No.: 0976-2558),
Volume 4, 2013, 16-22.

[7] Ganga, C. D. Singh, et al., Performance evaluation of a radiator in a diesel engine-a case study, Applied Thermal Engineering 19 (6) (1999) 625-639.

[8] Hui zhao et al, Controlled Atmosphere Brazing of Aluminum Heat Exchangers, Creative Thermal Solutions, Inc., Urbana, I 11. Feb 2013.

[9] International Copper Association (ICA), Aluminium Radiator in Trucks, USA 2004.

[10] J. Hirsch, Automotive Trends in Aluminium - The European Perspective, Institute of Materials Engineering Australasia Ltd Hydro Aluminium Deutschland GmbH R\&D, D-53014 Bonn, Germany MATERIALS FORUM VOLUME 28 - Published 2004.

[11] Jurgen Hirsch, Aluminium in Innovative Light-Weight Car, Hydro Aluminium Deutschland $\mathrm{GmbH}, \mathrm{R} \& \mathrm{D}, \mathrm{P}$. O. Box 2468-53117 Bonn, GermanyDesign Materials Transactions, Vol. 52, No. 5 (2011) pp. 818 to 824 Special Issue on Aluminium Alloys 2010 \#2011 The Japan Institute of Light Metals.

[12] K. Labisz et Al, Microstructure evaluation of the Al-Ti alloy with magnesium addition, journal of achievement in materials \& manufacturing Engineering Division of Materials Processing Technology, Management and Computer Techniques in Materials Science, Institute of Engineering Materials and Biomaterials, Silesian University of Technology ul. Konarskiego 18a, 44-100 Gliwice, Poland.

[13] Lee, Y.L. \& Hong, Y.T, Analysis of Engine Cooling Airflow including Non-uniformity over a Radiator, in International Journal of Vehicle Design,24, 1, 2000, 121-135.

[14] Lin, C, Specific Dissipation as a Technique for Evaluating Motor Car Radiator Cooling Performance, RMIT University, 2009.

[15] M. Bryan,et al, A2 1 Deep Space 1: Staying Cool, Journal of Physics Special Topics Department of Physics and Astronomy, University of Leicester. Leicester, LE1 7RH. Oct 19, 2012

[16] P. K. Nag, Thermodynamics, TMH Publication 2008.

[17] Randy Rundle, Automotive Cooling System Basics, 1999.

[18] Ray T. Bohacz, Engine Cooling Systems, 2007.

[19] Seth Daniel Oduro, Joshua Ampofo, Effect of Radiator Fins Blockage by Clay Soil on the Engine Cooling Temperature, International Journal of Engineering and Technology University of Education Winneba, Kumasi Campus Department of Design and Technology Education 2Kwame Nkrumah University of Science and Technology Kumasi, Ghana Volume 2 No. 6, June, 2012.

[20] Tata Toyo, Standard Radiator, Banco Radiator, Aluminium Radiator Manufacturers.

[21] William H. C. and Donald L. A, Automotive Fuel, Lubricating, and Cooling Systems, 1999.

[22] Yunus A. et al, Fundamental of Thermal-Fluid Sciences, 2005. 